\title{
PENGARUH USER EXPERIENCE (UX) DESIGN TERHADAP KEMUDAHAN PENGGUNA DALAM MENGGUNAKAN APLIKASI CARSWORLD
}

\author{
Joaldrik Ferad Wawolumaja \\ STIKOM InterStudi, Jakarta, Indonesia, \\ joaldrik.f@gmail.com \\ Martani Huseini \\ STIKOM InterStudi, Jakarta, Indonesia, \\ martani0703@yahoo.com \\ Kinkin Yuliaty Subarsa \\ STIKOM InterStudi, Jakarta, Indonesia, \\ kinkinsubarsa@unj.ac.id \\ Rosita Anggraini \\ STIKOM InterStudi, Jakarta, Indonesia, \\ rosita.tagor@gmail.com
}

\section{PENGARUH USER EXPERIENCE (UX) DESIGN TERHADAP KEMUDAHAN PENGGUNA DALAM MENGGUNAKAN APLIKASI CARSWORLD \\ ABSTRACT}

Rapid advances in digital technology are followed by intense competition for digital products. Digital product competition requires every business business to keep trying to facilitate their users as an effort to improve the User Experience of each user. User Experience (UX) Design is an important thing for digital businesses to pay attention to. The ease of user interaction or use of digital products will make the digital product widely used and anti to be abandoned. The better User Experience (UX) Design of a digital product, will make the user more comfortable in using it and as an impact, the user will become a loyal user and may be happy to recommend the product to others. Carsworld app, is the nearest car service online booking application. This application was created in 2018 and has been downloaded more than 10 thousand times on Playstore. This research will discuss about how User Experience (UX) Design affects the ease of users in using Carsworld application. The research was conducted by descriptive quantitative method based on 3 (Three) factors that need to be considered by user experience designer (UX) design as an effort to provide convenience for users of Carsworld application namely Usability, Look and Feel. The results of the study showed that User Experience (UX) Design affects the ease of users in using Carsworld application.

Keywords: EASE OF USER, CARSWORLD APP, USER EXPERIENCE (UX) DESIGN. 


\section{PENDAHULUAN}

Globalisasi dan kemajuan Teknologi Informasi saat ini membawa manusia kepada pengalaman-pengalaman baru dalam berinteraksi dengan teknologi. Kemudahan dalam melakukan setiap kegiatan kini dimungkinkan dan mendapatkan dukungan penuh dari Teknologi. Tahun 2020, berdasarkan Lembaga Riset Teknologi Gartner, yang dikutip oleh (Prabowo, Yanuarsari, \& Pramunendar, 2020) merupakan tahun kelahiran era baru yakni Internet of Thing Era. Pada Internet of Thing Era, setiap kegiatan masyarakat akan terintegrasi langsung dengan internet. Hal ini menyebabkan internet akan mendominasi beberapa bidang, termasuk budaya, ekonomi dan bisnis (Allam \& Jones, 2021).

Bidang Industri Otomotif, merupakan bidang industri yang selalu dibutuhkan pada saat ini atau pada era apapun selama transportasi masih dibutuhkan sebagai alat untuk mendukung pergerakan dan berpergian. Era Globalisasi dan serta revolusi industri yang telah maju dengan begitu pesat membawa bidang industri ini keranah yang jauh lebih tinggi daripada sebelumnya. Era industri Internet of Thing banyak memanjakan banyak pecinta otomotif dengan kemudahan-kemudahan. Diantaranya adalah kemudahan dalam melakukan service kendaraan mereka (Naser, Safari, \& Atmojo, 2020). Revolusi industri pada saat ini, telah berjalan dengan lebih jauh. Revolusi industri tidak hanya mendukung setiap perusahaan ataupun industri untuk tetap dekat dengan pelanggan mereka, namun untuk pengguna teknologi juga agar selalu mendapatkan kemudahan-kemudahan yang mereka inginkan (Abidin, 2018). Saat ini, revolusi industri telah memasuki point 5.0 atau revolusi "super smart society" (Demir, Döven, \& Sezen, 2019). Hadirnya revolusi pada point 5.0 diharapkan dapat mengecilkan kesenjangan antara teknologi dan social yang telah tercipta dan diakibatkan oleh revolusi industr 4.0. revolusi industri 5.0 menetapkan bahwa manusia (sebagai mahluk yang dapat berpikir secara kritis) merupakan penggerak utama teknologi (Puspita, Fitriani, Astuti, \& Novianti, 2020). Hal ini sangat berbeda jauh dengan revolusi industri 4.0 yang berfokus kepada kecerdasan buatan (Artificial Intelligence (AI)) (Prasetyo \& Trisyanti, 2019).

Dominasi penggunaan internet pada dunia bisnis pada saat ini semakin terasa dengan banyaknya produk digital bisnis yang bermunculan di internet. Banyaknya produk digital yang menawarkan layanan serupa mengancam pelaku bisnis yang kurang kreatif dan kurang aktif dalam meningkatkan layanan pada pengguna mereka. Pada era internet saat ini, pelaku bisnis produk digital dituntut untuk selalu aktif dan kreatif dalam menyediakan layanan digital (Sjödin, Parida, Kohtamäki, \& Wincent, 2020). Hal yang paling penting untuk diperhatikan oleh pelaku bisnis produk digital adalah desain antar muka pengguna dan User Experience mereka (Aziati, 2020) dan (Saputra, 2018).

Berdasarkan pendahuluan yang telah disampaikan, peneliti bertujuan untuk melakukan Analisa mengenai bagaimana User Experience (UX) Design berpengaruh terhadap kemudahan pengguna dalam menggunakan aplikasi Carsworld. Penelitian dilakukan dengan metode deskriptif kuantitatif berdasarkan 3 (Tiga) factor yang perlu diperhatikan oleh perancang User Experience (UX) design sebagai upaya memberikan kemudahan bagi pengguna aplikasi Carsworld yakni Usability, Look dan Feel (Paramitha, 2020). 


\section{KAJIAN PUSTAKA}

\section{User Experience (UX) Design}

Desain antar muka (Design Interface) merupakan penghubung antara suatu system (atau dalam hal ini produk bisnis digital) dengan penggunannya (Agarina, Sutedi, \& Karim, 2019). Seluruh proses interaksi antara pengguna dengan produk bisnis digital akan ditentukan dengan baik atau tidaknya desain antar muka (Kristianto, 2020). Desain antar muka yang mudah dipahami akan memberikan User Experience yang baik kepada pengguna. Sebaliknya, desain antar muka yang buruk dan tidak mudah untuk dipahami akan memberikan User Experience yang buruk pula. User Experience (UX) design, karenanya menjadi sesuatu yang wajib untuk diperhatikan oleh pengembang produk digital bisnis (Luther, Tiberius, \& Brem, 2020). User Experience (UX) design yang baik, berperan penting terhadap penilaian pengguna terhadap produk digital bisnis secara keseluruhan. Tanggapan dan penilaian yang baik dari pengguna terhadap User Experience (UX) design dapat menjadi daya Tarik bagi calon pengguna baru untuk menggunakan produk bisnis digital (Fitriana \& Yanto, 2020). Lebih jauh, tanggapan dan penilaian dari pengguna ini dapat digunakan sebagai imbal balik untuk pebisnis agar dapat merancang system yang lebih baik lagi dan lebih memudahkan pengguna dalam berinteraksi dengan aplikasi. Berdasarkan (Paramitha, 2020) terdapat 3 (Tiga) factor yang perlu diperhatikan oleh perancang User Experience (UX) design yakni Usability, Look dan Feel.

\section{Faktor Penting dalam User Experience (UX) design}

Berdasarkan yang telah disebutkan pada pendahuluan, terdapat 3 (Tiga) factor yang perlu diperhatikan oleh perancang User Experience (UX) design yakni Usability, Look dan Feel (Paramitha, 2020). Ketiga factor ini merupakan hal yang harus dilihat oleh developer sebagai upaya untuk meningkatkan kemudahan pengguna dan User Experience mereka.

Ketiga factor penting dalam perancangan User Experience (UX) design akan dijabarkan sebagai berikut ini:

\section{Usability (Kegunaan)}

Usability merupakan sejauh mana produk bisa dipergunakan oleh pengguna dalam mencapai tujuan tertentu hingga mencapai tujuan yang efektif, efisiensi dan mencapai kepuasan terhadap pengguna dalam konteks penggunaan. Usability merupakan kualitas yang dipergunakan dalam mengevaluasi mudahnya user interface digunakan (Nanda, 2020) and (Guimarães, et al., 2020).

Menurut ISO 9241-210 user experience merupakan persepsi dan respon yang merupakan dari pengguna sebagai reaksi dalam penggunaan sebuah produk, system, ataupun service. User experience merupakan hal yang dirasakan user kesenangan dan kepuasan dalam menggunakan produk, melihat produk, hingga memegang produk. Usability memiliki kriteria yaitu (Bortko, Bartków, Jankowski, Kuras, \& Sulikowski, 2019):

\section{- Efektif}

Sebuah produk yang efektif harus digunakan dalam mengerjakan tugas tertentu atau bisa dikatakan bagaimana produk dalam menjalankan tugas yang bisa dilakukan. 
- Efisiensi

Efisiensi dikaitkan dengan pencapaian tujuan dalam menggunakan sebuah produk tersebut.

\section{- Safety}

Safety disini merupkan pencegahan pengguna dari kedaan yang bahaya yang tidak diinginkan. Hal ini akan membuat pengguna menjadi aman saat menggunakan produk dan pencegahan pada hal lainnya.

\section{- Utility}

Utility merupakan hal yang berkaitan dengan sejauh mana produk dapat memberikan fungsi yang baik dan pengguna dapat melakukan hal yang di inginkan dalam produk tersebut.

\section{- Learnability}

Mudah untuk dipelajari pada sebuah produk sebelum produk di gunakan. Dalam mempelajari produk seharusnya pengguna tidak menghabiskan terlalu banyak waktu dalam mempelajari sebuah produk yang akan dipergunakan.

\section{- Memorability}

Dalam hal ini merupakan nilai apabila produk sudah diperlajari, maka akan teringat oleh pengguna bagaimana produk nantinya akan dipergunakan. Pada umumnya UX memiliki tiga karakteristik yaitu: pengguna dapat berinteraksi dalam produk atau system, pengalaman pengguna yang menarik dan dapat di telusur dan di ukur.

Berdasarkan Frank Guo dalam (Rizaldy \& Dirgahayu, 2020) UX memiliki tiga elemen yaitu:

\section{1) Valueable}

Produk yang memiliki fitur yang sesuai dengan pengguna. Meski produk mudah dalam digunakan pengguna namun apabila tidak sesuai dengan adanya kebutuhan pengguna maka produk ini belum memiliki nilai yang baik.

\section{2) Adoptability}

Produk memiliki harga dan nilai namun tidak mudah untuk dimiliki dengan itu produk tersebut belum bias dikatakan memiliki UX yang baik. Produk yang mudah dimiliki, mudah untuk dibeli dan mudah untuk di download. Hal ini akan mempermudah pengguna dalam menggunakan produk tersebut.

\section{3) Desirability}

Hal ini merupakan hal yang berkaitan dengan daya tarik emosi. Dengan ini pengguna memiliki pengalaman yang baik dalam produk tertentu. Apabila produk memiliki empat elemen yang terdapat diatas maka produk tersebut memiliki kualitas UX yang baik.

Usability akan mewakili bagaimana kemudahan pengguna dalam menjalankan fungsi aplikasi, memahami konten yang tersedia, kemudahan dalam melihat tata letak serta bagaimana kemudahan pengguna dalam menemukan informasi yang mereka inginkan, kemudian bagaimana pemenuhan representasi system yang berada pada aplikasi (Prabowo, Yanuarsari, \& Pramunendar, 2020), (Aries, Ranius, \& Saputri, 2017) dan (Paramitha, 2020). 


\section{Look (Penampilan)}

Memiliki look atau penampilan yang menarik merupakan hal yang penting dalam pembuatan sebuah aplikasi. Hal ini akan memberikan kemudahan bagi para pengguna dalam melakukan access. Look atau penampilan yang baik akan memberikan kenyamanan pengguna dalam mengingat aplikasi dan bagaimana menggunakannya dengan mudah.

Look akan mewakili apa alasan pengguna untuk terus menggunakan aplikasi yang didasarkan kepada kejelasan penyajian fitur dan menu aplikasi, kesesuaian tampilan desain grafis, serta kesuaian dari warna pilihan yang berada di dalam aplikasi (Münzer, 2020) dan (Paramitha, 2020).

\section{3. $\quad$ Feel (Perasaan)}

Feel mewakili bagaimana perasaan pengguna dalam menggunakan aplikasi, perasaan ini meliputi kemudahan yang dirasakan pengguna pada saat menggunakan aplikasi, apakah aplikasi telah mampu memberikan setiap hal yang diinginkan oleh pengguna dan apakah pengguna akan menggunakan aplikasi tersebut kembali (Biduski, Bellei, Rodriguez, Zaina, \& Marchi, 2020), (Park, Lee, Seo, \& Billinghurst, 2020) dan (Paramitha, 2020).

\section{Kemudahan Penggunaan}

Kemudahan penggunaan serta kenyamanan merupakan aspek penting dalam membangun suatu system produk digital bisnis ( $\mathrm{Li}, \mathrm{Zhao}, \mathrm{Xu}, \& \mathrm{Pu}, 2020)$. Kesuksesan system diantara, ditentukan oleh kemampuan system tersebut untuk memberikan pengalaman yang baik pada penggunanya (User Experience) (Yoon \& Suh, 2020). Sebagai penghubung antara pengguna dan system, desain antar muka system berperan penting. Peran desain antar muka system ini termasuk perannya dalam memberikan kemudahan serta pengalaman yang menyenangkan terhadap pengguna produk bisnis digital (Shin, Zaid, \& Ibahrine, 2020). Sehingga, secara tidak langsung, dapat disimpulkan bahwa desain antar muka berpengaruh terhadap pengalaman pengguna (User Experience (UX) design). Oleh karena itu, sangat penting dilakukannya pembangunan sebuah desain yang didasarkan pada User Experience (UX) design untuk meningkatkan kemudahan pengguna (Laksono, 2020).

\section{Aplikasi Carsworld}

Aplikasi Carsworld merupakan aplikasi booking online service mobil yang didirikan pada tahun 2018. Carsworld mengupayakan 3 (tiga) hal dalam mengembangkan teknologinya yakni: kecepatan, inovasi dan terpercaya dalam memberikan layanan yang terbaik bagi seluruh masyarakat Indonesia. Aplikasi Carsworld telah di download sebanyak lebih dari 10 ribu pengguna pada aplikasi Play Store (Carsworld, 2018). Serta mendapatkan tanggapan yang beragam dari para penggunanya. Beberapa pengguna menyebutkan kepuasan mereka dalam menggunakan aplikasi Carsworld dan beberapa menyatakan sebaliknya.

Teknologi membuat apapun menjadi lebih simple, teknologi Carsworld membuat aplikasi yang mehubungkan layanan otomotif dengan satu ekosistem. Ekosistem yang dimaksud menrupakan masyarakat pemilik transportasi otomotif yang merupakan pengguna aplikasi Carsworld. Aplikasi ini menfokuskan diri kepada memberikan kecepatan, inovasi terhadap Booking Service Mobil Online serta dapat dipercaya. Aplikasi 
Carsworld memberikan solusi terbaik dan simple bagi para pecinta otomotif dalam melakukan Booking untuk perbaikan mobil mereka (Carsworld, 2018). Beberapa menu yang berada dalam aplikasi Carsworld meliputi beberapa pilihan untuk melakukan service, seperti service mesin, transisi dan kopling, perbaikan AC mobil, perbaikan rem mobil, suspense dan steering, perbaikan ban mobil, pergantian oli, penggantian baterai maupun service umum (Carsworld, 2018). Selain itu, aplikasi Carsworld juga menyediakan paket service untuk service yang lebih berkala. Paket service ini dapat digunakan bagi para pengguna aplikasi Carsworld yang menginginkan service secara menyeluruh terhadap kendaraan yang dimilikinya. Carsworld memberikan pengalaman pengguna (UX) yang mana mereka menyediakan aplikasi untuk service mobil (Annisa, Suwandari, \& Adi, 2019). Layanan ini akan berkaitan dengan aktivitas dan kualitas hidup user. Pengalaman yang ingin ditanamkan oleh Carsworld adalah menciptakan pengalaman dalam menggunakan layanan service mobil yang dapat membantu kebutuhan user, dengan membantu tanpa harus antri untuk booking service dan apabila user sibuk tidak bisa membawa mobilnya untuk service ke bengkel, aplikasi Carsworld menyediakan layanan home service delivery.

User diberikan pengalaman kemudahan dalam hidup dengan adanya konsep layanan dari aplikasi Carsworld ini. hal ini akan menjadi suatu dukungan aplikasi Carsworld menyalurkan pengalaman dalam penggunaannya karena pada halaman muka akan memberikan informasi fitur-fitur layanan yang aplikasi Carsworld miliki. Dengan memahami fitur yang dimiliki aplikasi Carsworld menekankan fitur pada fase awal, hal ini akan membuat pembentukan proses untuk tindakan user dalam menggunakan aplikasi Carsworld. Kekurangan yang dirasakan user adalah pengiriman kode autentifikasi yang dikirim untuk user sangat lama kadang tidak masuk ke nomor handphone user.

\section{METODE PENELITIAN}

Metodologi penelitian terhadap "Pengaruh User Experience (UX) design terhadap kemudahan pengguna menggunakan aplikasi Carsworld" akan digambarkan pada Gambar 1.

Pada Gambar 1 ditunjukkan, penelitian akan dimulai dari penentuan object studi lapangan (peneliti memutuskan dalam hal ini adalah aplikasi Carsworld), menentukan focus penelitian (focus penelitian dalam jurnal ini adalah bagaimana pengaruh User Experience (UX) Design Terhadap Kemudahan Pengguna Dalam Menggunakan Aplikasi Carsworld), kemudian, peneliti akan melakukan identifikasi dan perumusan masalah, menentukan tujuan penelitian, melakukan pengumpulan data (menentukan sampel penelitian, Melakukan studi pustaka terkait pernyataan penelitian, dan Mengumpulkan hasil korespondensi Pengguna), setelah itu, peneliti akan melanjutkan dengan melakukan Perhitungan hasil dan perumusan penelitian, setelah semua hal tersebut diatas dilakukan maka penelitian ini telah selesai. 


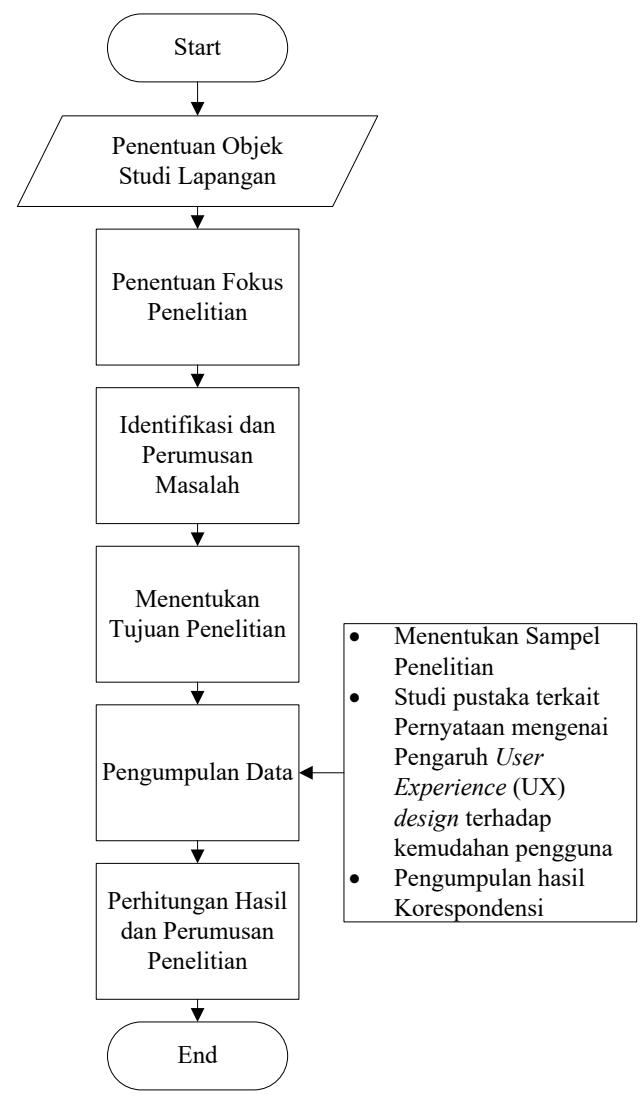

Gambar 1. Metodologi Penelitian Pengaruh User Experience (UX) design terhadap kemudahan pengguna menggunakan aplikasi Carsworld

\section{Pengumpulan Data}

Pengumpulan data dilakukan dengan melakukan penyebaran kuisioner. Setiap factor pembangun User Experience (UX) design akan dibuatkan pertanyaan atas User Experience (UX) yang akan dinyatakan dalam kuisioner. Kuisioner dibagikan kepada responden dengan rentang usia 25 tahun keatas dengan jumlah sebanyak 30 responden yang telah dihitung menggunakan rumus Slovin dengan ukuran populasi penelitian sebesar 43 orang dan mengambil 10\% sebagai tingkat kesalahan. Rumus Slovin yang digunakan, didasarkan pada (Dzulkifli, Arifin, \& UmmuSalmah, 2020) adalah sebagai berikut:

$$
n=\frac{N}{N(e)^{2}+1}
$$

Dimana:

$\mathrm{n}=\quad$ Ukuran Sampel yang menjadi objek penelitian

$\mathrm{N}=\quad$ Ukuran Populasi yang menjadi objek penelitian (pengguna aplikasi Carsworld dengan minimal telah pernah menggunakan dan mencoba bertransaksi dengan aplikasi sebanyak 2 (dua) kali.

$\mathrm{e}=\quad$ Persentase kesalahan pengambilan sampel yang ditolelir 
Sehingga, karena ukuran populasi adalah sebesar 43 Orang (populasi merupakan pelanggan yang telah memiliki dan telah menggunakan aplikasi Carsworld sebelumnya) dan mengambil tingkat kesalahan $10 \%$, maka:

$$
n=\frac{43}{43(10 \%)^{2}+1}=30 \text { Sampel }
$$

Sehingga, sampel yang digunakan dalam penelitian ini adalah sebanyak 30 pelanggan yang telah memiliki dan telah menggunakan aplikasi Carsworld sebelumnya.

Penelitian dilakukan dengan metode deskriptif kuantitatif berdasarkan 3 (Tiga) factor yang perlu diperhatikan oleh perancang User Experience (UX) design sebagai upaya memberikan kemudahan bagi pengguna aplikasi Carsworld yakni Usability, Look dan Feel yang didasarkan pada teori dari (Paramitha, 2020).

Pada ketiga factor yang telah dijabarkan, berdasarkan definisi serta acuan tersebut, peneliti akan membuat variable unsur User Experience (UX) design yang akan ditanyakan kedalam kuisioner. Hasil yang diinginkan oleh peneliti dalam hal ini adalah untuk mengetahui apakah User Experience (UX) design berpengaruh terhadap kemudahan pengguna dalam menggunakan aplikasi Carsworld.

Peneliti kemudian akan merumuskan pernyataan untuk kuisioner yang akan disebarkan pada 33 sampel penelitian. Pernyataan yang dibuat berdasarkan ketiga Faktor Penting dalam User Experience (UX) design (Usability, Look dan Feel). Variabel penelitian dapat dilihat pada Tabel 1 berikut:

Tabel 1. Variabel Penelitian

\begin{tabular}{|c|c|}
\hline Variabel Penelitan & Inisal \\
\hline Variabel Usability (Kegunaan) & $\mathrm{X} 1$ \\
\hline Variabel Look (Penampilan) & $\mathrm{X} 2$ \\
\hline Variabel Feel (Perasaan) & $\mathrm{X} 3$ \\
\hline User Experience (UX) design & $\mathrm{Y}$ \\
\hline
\end{tabular}

Kuisioner yang disebarkan akan memiliki 2 (dua) skala penilaian yakni "ya" dan "tidak". Sehingga, peneliti akan memberikan hasil yang lebih pasti terhadap kemudahan pengguna. 


\section{Hasil Penelitian}

\section{HASIL DAN PEMBAHASAN}

\section{Carsworld Aplikasi Dunia Otomotif}

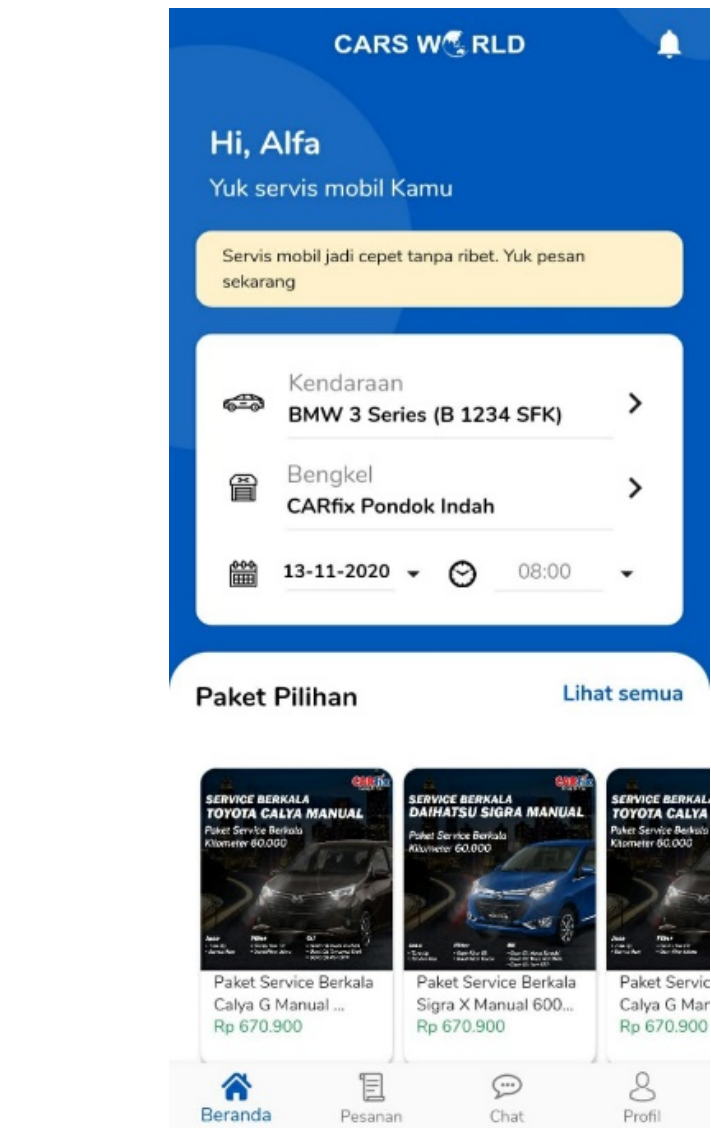

Gambar 2. User Interface "Halaman Awal" Aplikasi Carsworld

Sumber: (Carsworld, 2018)

PT. Industri dan Perdagangan Bintraco Dharma Tbk melalui anak perusahaan mereka yang bernama PT Carsworld Digital Indonesia merilis aplikasi baru untuk dunia otomotif digital yaitu Carsworld. Direktur Utama Bintraco Dharma Sebastianus Harno Budi mengatakan aplikasi carsworld merupakan aplikasi yang disajikan untuk para pecinta otomotif di Indonesia. Aplikasi Carsworld ni merupakan aplikasi booking servis mobil dengan via online yang akan memberikan kemudahan bagi pecinta otomotif. Carsworld memberikan layanan untuk booking servis layanan ini akan memberikan kemudahan untuk customer, apabila ingin melakukan servis terhadap kendaraannya tanpa harus antri untuk daftar servis.

Aplikasi Carsworld memberikan layanan yang dapat mendekatkan pelanggan dengan layanan otomotif yang mereka inginkan. Aplikasi Carsworld dalam layanan bengkel memberikan transparansi dalam melihat biaya servis kendaraan yang mereka servis. Dengan adanya layanan booking online ini akan sangat memberikan kemudahan untuk pelanggan. Carsworld melihat adanya problem yang saat ini sering ditemui oleh pemilik mobil, yakni kebingungan akan harga service mobilnya, selain itu pemilik mobil juga tidak mengetahui berapa lama waktu untuk melakukan service mobil serta service jenis apa yang harus mereka pilih. Dalam layanan booking untuk service, pengguna harus melakukan booking tiga hari sebelumnya waktu pengerjaan. 
Selain layanan booking service yang datang ke bengkel yang berada di sekitar pemilik mobil, Carsworld juga menyediakan jasa service home delivery. Dengan adanya jasa ini pemilik mobil hanya tingga diam dirumah atau kantor kemudian mekanik akan mengambil mobil konsumen untuk melakukan service. Hal ini akan sangat memberikan kemudahan untuk pemilik mobil, terlebih lagi hal ini akan memberikan keutungan bagi orang yang sangat sibuk dan tidak bisa membawa mobilnya ke bengkel.

Pada waktu kedepannya Carsworld berharap bisa mengembangkan aplikasinya untuk pelayanan pembelian mobil, accessories mobil, dan lelang mobil pada aplikasi Carsworld. Dengan harapan pengembangan kedepan untuk aplikasi ini Carsworld dirancang untuk memenuhi gaya hidup para pecinta otomotif saat ini yang sudah serba digital. Dengan pengembangan seperti itu akan memberikan kenyamanan untuk para pecinta otomotif dalam membeli mobil baru, memperoleh biaya servis dengan transparan, pembelian accessories mobil dengan harga yang terbaik, perbaikan mobil yang baik, menjual mobil customer hingga membeli mobil baru atau used car dengan standar kualitas yang terbaik. Demi memberikan pelayanan terbaik, perancang aplikasi Carsworld bekerjasama dengan bengkel mobil yang professional dan telah terpercaya, yang memberikan pelayanan dan kualitas terbaik dalam memanjakan pelanggan atau pemilik kendaraan yang mana pada saat ini bisa memesan service dengan melalui layanan aplikasi Carsworld (Wicaksono, 2018). Munculnya inovasi dan kehadiran layanan yang digital dari aplikasi Carsworld akan memungkinkan pemilik kendaraan menggunakan layanan servis mobil tanpa repot harus pergi ke bengkel.

Seiring digunakannya aplikasi Carsworld memberikan User Experience, yang memberikan banyak masukan dari user (Alrio, Kharisma, \& Az-Zahra, 2018) Dengan adanya hal ini Carsworld memberikan peningkatan pelayanan terhadap aplikasinya agar lebih nyaman untuk dinikmati oleh user. Peningkatan tersebut memberikan Carsworld belajar dari pengalaman sebelumnya yang mana saat login aplikasi memberikan kode OTP yang lama, bahkan tidak terkirim ke nomor user. Hal ini membuat Carsworld melakukan peningkatan dan memberikan hasil dengan komentar ulasan baik (Carsworld, 2018).

\section{Analisis User Experience (UX) design Terhadap Kemudahan Pengguna Aplikasi Carsworld}

Berdasarkan hasil studi literatur yang dilakukan oleh peneliti, peneliti memutuskan akan melakukan Analisa pada pengaruh 3 (Tiga) factor yang perlu diperhatikan oleh perancang User Experience (UX) design berdasarkan (Paramitha, 2020) yakni Usability, Look dan Feel terhadap kemudahan pengguna aplikasi Carsworld. Kuisioner yang dibuat oleh peneliti akan didasarkan pada penjabaran yang telah dijelaskan pada point "Faktor Penting dalam User Experience (UX) design" dalam bagian "Metode Penelitan".

Berikut ini akan dijabarkan kuesioner penelitian yang disajikan dalam bentuk tabulasi data statistic sebagai berikut: 
PENGARUH USER EXPERIENCE (UX) DESIGN TERHADAP KEMUDAHAN

PENGGUNA DALAM MENGGUNAKAN APLIKASI CARSWORLD

\section{Usability (Kegunaan)}

Tabel 1. Kuisioner User Experience $(U X)$ design pada Variabel Usability (Kegunaan)

Sumber: Hasil Olah Peneliti

\begin{tabular}{|c|c|c|c|c|c|}
\hline \multicolumn{6}{|c|}{ Variabel Usabilitx (Kegunaan) } \\
\hline \multirow[b]{2}{*}{ No. } & \multirow{2}{*}{$\begin{array}{c}\text { Pertanyaan } \\
\text { Kuisioner } \\
\text { Terhadap } \\
\text { Variabel Usabilitx } \\
\text { (Kegunaan) } \\
\end{array}$} & \multicolumn{2}{|c|}{ Frekuensi } & \multicolumn{2}{|c|}{ Persentase } \\
\hline & & Ya & Tidak & Ya & Tidak \\
\hline 1 & $\begin{array}{l}\text { Apakah setiap } \\
\text { fungsi (booking } \\
\text { Service Mobil } \\
\text { Online, pemesanan } \\
\text { pilihan service, } \\
\text { paket service } \\
\text { mobil, dsb) pada } \\
\text { Aplikasi Carsword } \\
\text { mudah untuk anda } \\
\text { dijalankan? }\end{array}$ & 26 & 4 & $87 \%$ & $13 \%$ \\
\hline 2 & $\begin{array}{l}\text { Apakah setiap } \\
\text { konten yang } \\
\text { tersedia dalam } \\
\text { aplikasi Carsword } \\
\text { mudah untuk anda } \\
\text { pahamidan anda } \\
\text { jalankan? }\end{array}$ & 27 & 3 & $90 \%$ & $10 \%$ \\
\hline 3 & $\begin{array}{l}\text { Apakah anda dapat } \\
\text { dengan mudah } \\
\text { mengingat tata } \\
\text { letak serta konten } \\
\text { pada aplikasi } \\
\text { Carsword? }\end{array}$ & 25 & 5 & $83 \%$ & $17 \%$ \\
\hline 4 & $\begin{array}{l}\text { Apakah anda dapat } \\
\text { dengan mudah } \\
\text { menemukan } \\
\text { Informasi seputar } \\
\text { Booking, Online } \\
\text { Service Mobil yang } \\
\text { anda butuhkan } \\
\text { dalam aplikasi } \\
\text { Carsword? }\end{array}$ & 26 & 4 & $87 \%$ & $13 \%$ \\
\hline 5 & $\begin{array}{l}\text { Apakah aplikasi } \\
\text { "Carsword" } \\
\text { memenuhi } \\
\text { representasi secara } \\
\text { sistem pelayanan } \\
\text { sebagai } \\
\text { aplikasi penyedia } \\
\text { jasa Beoking } \\
\text { Online Service } \\
\text { Mobil yang anda } \\
\text { cari? }\end{array}$ & 26 & 4 & $87 \%$ & $13 \%$ \\
\hline $\begin{array}{l}\mathrm{Ra} \\
\mathrm{Ter}\end{array}$ & $\begin{array}{l}\text { rata Persentase Jaw } \\
\text { dap Variabel Usabi }\end{array}$ & & $\begin{array}{l}\text { ioner } \\
\text { inaan) }\end{array}$ & $87 \%$ & $13 \%$ \\
\hline
\end{tabular}


PENGARUH USER EXPERIENCE (UX) DESIGN TERHADAP KEMUDAHAN

PENGGUNA DALAM MENGGUNAKAN APLIKASI CARSWORLD

\section{Look (Penampilan)}

Tabel 2. Kuisioner User Experience (UX) design pada Variabel Look (penampilan)

\begin{tabular}{|c|c|c|c|c|c|}
\hline \multicolumn{6}{|c|}{ Variabel Look (Penampilan) } \\
\hline \multirow[b]{2}{*}{ No. } & \multirow{2}{*}{$\begin{array}{c}\text { Pertanyaan } \\
\text { Kuisioner } \\
\text { Terhadap } \\
\text { Variabel Look } \\
\text { (Penampilan) }\end{array}$} & \multicolumn{2}{|c|}{ Frekuensi } & \multicolumn{2}{|c|}{ Persentase } \\
\hline & & $\mathbf{Y a}$ & Tidak & $\mathbf{Y a}$ & Tidak \\
\hline 6 & $\begin{array}{l}\text { Apakah setiap } \\
\text { fitur dan menu } \\
\text { aplikasi pada } \\
\text { Carsword, telah } \\
\text { disajikan dengan } \\
\text { jelas? }\end{array}$ & 28 & 2 & $93 \%$ & $7 \%$ \\
\hline 7 & $\begin{array}{l}\text { Apakah tampilan } \\
\text { Desain Grafis } \\
\text { aplikasi } \\
\text { Carsword telah } \\
\text { sesuai dan baik? }\end{array}$ & 25 & 5 & $83 \%$ & $17 \%$ \\
\hline 8 & $\begin{array}{l}\text { Apakah } \\
\text { penggunaan } \\
\text { warna tampilan } \\
\text { aplikasi } \\
\text { Carsword, telah } \\
\text { sesuai? }\end{array}$ & 24 & 6 & $80 \%$ & $20 \%$ \\
\hline \multicolumn{4}{|c|}{$\begin{array}{l}\text { Rata-rata Persentase Jawaban Kuisioner } \\
\text { Terhadap Variabel Look (Penampilan) }\end{array}$} & $86 \%$ & $14 \%$ \\
\hline
\end{tabular}

Sumber: Hasil Olah Peneliti

\section{Feel (Perasaan)}

Tabel 3. Kuisioner User Experience (UX) design pada Variabel Feel (Perasaan)

\begin{tabular}{|c|c|c|c|c|c|}
\hline \multicolumn{6}{|c|}{ Variabel Eeel (Perasaan) } \\
\hline \multirow[b]{2}{*}{ No. } & \multirow{2}{*}{$\begin{array}{c}\text { Pertanyaan } \\
\text { Kuisioner Terhadap } \\
\text { Variabel Eeel } \\
\text { (Perasaan) }\end{array}$} & \multicolumn{2}{|c|}{ Frekuensi } & \multicolumn{2}{|c|}{ Persentase } \\
\hline & & $\mathbf{Y a}$ & Tidak & $\mathbf{Y a}$ & Tidak \\
\hline 9 & $\begin{array}{l}\text { Apakah aplikasi } \\
\text { Carsword mudah } \\
\text { untuk anda gunakan? }\end{array}$ & 28 & 2 & $93 \%$ & $7 \%$ \\
\hline 10 & $\begin{array}{l}\text { Apakah aplikasi } \\
\text { Carswordmemberikan } \\
\text { setiap hal yang anda } \\
\text { perlukan untuk } \\
\text { Boeking Service mobil } \\
\text { Online? }\end{array}$ & 29 & 1 & $97 \%$ & $3 \%$ \\
\hline 11 & $\begin{array}{l}\text { Apakah anda akan } \\
\text { menggunakan aplikasi } \\
\text { Carsword kembali } \\
\text { untuk melakukan } \\
\text { Booking Service mobil } \\
\text { Online? }\end{array}$ & 29 & 1 & $97 \%$ & $3 \%$ \\
\hline \multicolumn{4}{|c|}{$\begin{array}{l}\text { Rata-rata Persentase Jawaban Kuisioner } \\
\text { Terhadap Variabel Feel (Perasaan) }\end{array}$} & $96 \%$ & $4 \%$ \\
\hline
\end{tabular}

Sumber: Hasil Olah Peneliti 


\section{Pembahasan}

Pembahasan mengenai hasil temuan akan disajikan dalam bentuk grafik dan ringkasan penlinaian serta analisa dari ketiga factor User Experience (UX) design yang mempengaruhi kemudahan pengguna dalam menggunakan aplikasi Carsworld akan disajikan sebagai berikut:

\section{Usability (Kegunaan)}

Elemen Usability atau kegunaan, seperti yang telah disebutkan, mewakili bagaimana pengguna merasa bahwa aplikasi Carsworld berguna dan mudah untuk dijalankan, dipahami serta diingat kemudian memberikan informasi yang tepat dan memeberikan dukungan yang memadai bagi pengguna dalam melakukan Booking Service Mobil Online.

Berdasarkan hasil kuisioner didapatkan bahwa 87\% (Delapan Puluh Tujuh Persen) pengguna menyatakan kesetujuan mereka bahwa aplikasi Carsworld telah memenuhi factor Usability, sedang sisanya 13\% (Tiga Belas Persen) menyatakan bahwa mereka tidak setuju bahwa aplikasi Carsworld memenuhi factor Usability. Grafik perbandingan akan disajikan pada gambar 3 .

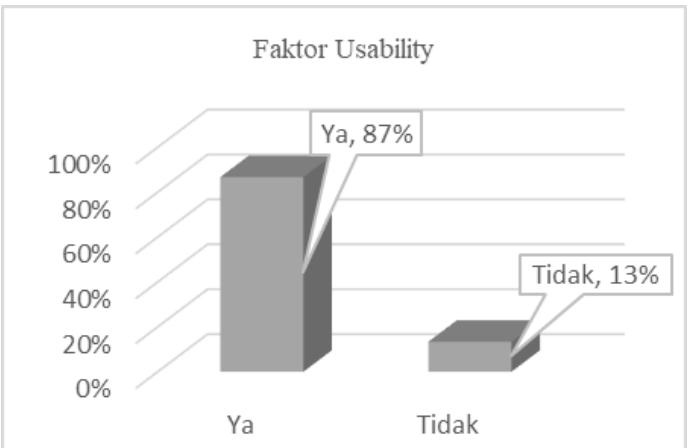

Gambar 3. Grafik Penilaian User Experience (UX) design pada Faktor Usability (Kegunaan) Sumber: Hasil Olah Peneliti

Berdasarkan Gambar 3, peneliti mengambil kesimpulan bahwa User Experience $(U X)$ design pada factor Usability pada aplikasi Carsworld dikategorikan sebagai "cukup baik" dengan perolehan angka persentase untuk setuju yang sangat tinggi yakni $87 \%$. Perolehan angka terhadap persentase tidak setuju hanya berada pada 13\% (Tiga Belas Persen). Sehingga, kesimpulan akhir peneliti menyatakan bahwa, factor Usability pada User Experience (UX) design mempengaruhi kemudahan pengguna dalam menggunakan aplikasi Carsworld sebesar 87\% (Delapan Puluh Tujuh Persen).

Hal yang perlu untuk ditingkatkan oleh developer Carsworld terkait dengan factor ini adalah bagaimana pengaturan dan penyajian tata letak yang baik. Karena berdasarkan responden, point tata letak yang memiliki skor terendah untuk kesetujuan. Perbaikan developer terhadap pengaturan tata letak diharapkan mampu meningkatkan kemudahan pengguna dalam menggunakan aplikasi Carswold.

\section{Look (Penampilan)}

Elemen Look atau penampilan, mewakili banyak hal mengenai tampilan dan konten aplikasi. Dalam factor ini, hal yang paling penting adalah bagaimana tampilan fitur, desain serta warna dapat sesuai dan dapat dengan jelas terlihat pada aplikasi agar 
pengguna mampu secara mudah mengoperasikan setiap fungsi yang ada di dalam aplikasi Carsworld. Factor Look menuntut aplikasi Carsworld untuk mampu secara baik menarik pengguna dengan menyajikan tampilan desain aplikasi yang baik, penyesuaian konten agar mudah diingat dan pemilihan warna yang sesuai. Factor Look harus memberikan dukungan yang memadai bagi pengguna dalam melakukan Booking Service Mobil Online terutama dalam hal tampilan aplikasi.

Berdasarkan hasil kuisioner didapatkan bahwa 86\% (Delapan Puluh Enam Persen) pengguna menyatakan kesetujuan mereka bahwa aplikasi Carsworld telah memenuhi factor Look, sedang sisanya 14\% (Empat Belas Persen) menyatakan bahwa mereka tidak setuju bahwa aplikasi Carsworld memenuhi factor Look. Grafik perbandingan akan disajikan pada gambar 4 .

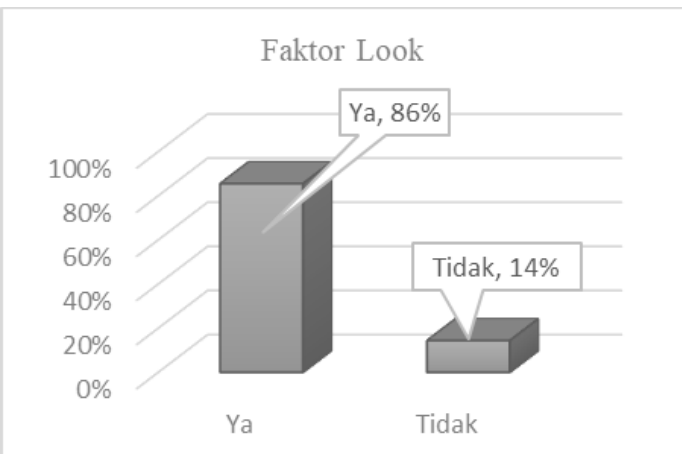

Gambar 4. Grafik Penilaian User Experience (UX) design pada Faktor Look (Penampilan) Sumber: Hasil Olah Peneliti

Berdasarkan Gambar 4, peneliti mengambil kesimpulan bahwa User Experience $(U X)$ design pada factor Look pada aplikasi Carsworld dikategorikan sebagai "cukup baik" dengan perolehan angka persentase untuk setuju yang sangat tinggi yakni $86 \%$ (Delapan Puluh Enam Persen). Perolehan angka terhadap persentase tidak setuju hanya berada pada 14\% (Empat Belas Persen). Sehingga, kesimpulan akhir peneliti menyatakan bahwa, factor Look pada User Experience (UX) design mempengaruhi kemudahan pengguna dalam menggunakan aplikasi Carsworld sebesar $86 \%$.

Kemudahan yang dimaksud dengan terpenuhinya factor look sebanyak $86 \%$ (Delapan Puluh Enam Persen) mencakup kemudahan karena fitur menu untuk aplikasi Booking Online Service Mobil Carsworld telah disajikan dengan jelas. Penyajian menu aplikasi serta fitur dalam aplikasi Carsworld mendapatkan angka yang cukup tinggi yakni 93\%. Tampilan desain grafis yang baik memperoleh angka 83\% (Delapan Puluh Tiga Persen), hal ini berarti factor Look dalam desain grafis yang baik mampu mempengaruhi kemudahan pengguna sebanyak 83\% (Delapan Puluh Tiga Persen). Sayangnya, menurut peneliti yang didasarkan pada rekap responden, pemilihan warna untuk desain aplikasi Carsworld dianggap kurang sesuai. Hal ini ditandai dengan diperolehnya angka hanya $80 \%$ (Delapan Puluh Persen) pada factor penggunaan warna tampilan. Tentunya hal ini harus menjadi masukan bagi para developer aplikasi Carsworld dalam meningkatkan kemudahan pengguna dalam menggunakan aplikasi Carsworld dan melakukan Booking Online Service Mobil.

\section{Feel (Perasaan)}

Factor feel mewakili bagaimana perasaan "feel" pengguna dalam menggunakan aplikasi Carsworld. Kesimpulan dari factor ini akan mencakup apakah pelanggan 
kemungkinan akan menggunakan aplikasi untuk jangka waktu yang Panjang. Dalam factor ini, hal yang perlu diperiksa adalah kemudahan aplikasi pada saat digunakan untuk melakukan Booking Online Service Mobil, apakah setiap hal yang diperlukan pengguna dalam melakukan Booking Online Service Mobil sudah terpenuhi seluruhnya serta apakah pengguna akan menggunakan kembali aplikasi Carsworld untuk melakukan Booking Online Service Mobil.

Kuisioner yang dilakukan oleh peneliti mendapatkan bahwa rata-rata pengguna aplikasi Carsworld merasakan "feel" yang baik saat menggunaka aplikasi. Hal ini ditandai dengan penilaian terhadap "Ya" sebesar 96\% (Sembilan Puluh Enam Persen), sedang sisanya 4\% (Empat Persen) menyatakan "Tidak". Grafik penilaian User Experience (UX) Design terhadap factor Feel akan disajikan pada Gambar 5.

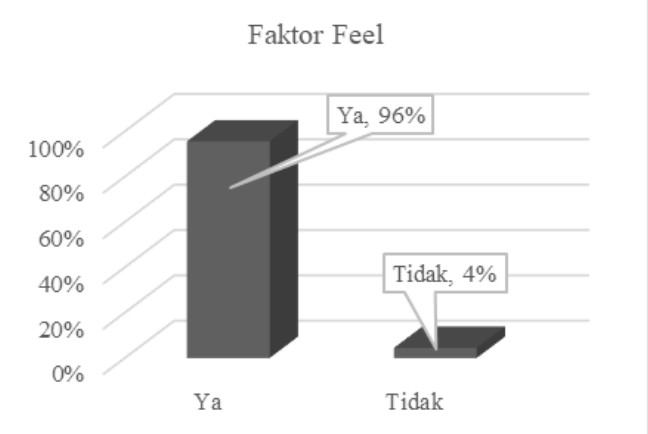

Gambar 5. Grafik Penilaian User Experience (UX) design pada Faktor Feel (Perasaan) Sumber: Hasil Olah Peneliti

Berdasarkan Gambar 5, peneliti mengambil kesimpulan bahwa User Experience $(U X)$ design pada factor Feel pada aplikasi Carsworld dikategorikan sebagai "sangat baik" dengan perolehan angka persentase untuk setuju yang sangat tinggi yakni $96 \%$ (Sembilan Puluh Enam Persen). Perolehan angka terhadap persentase tidak setuju hanya berada pada 4\% (Empat Persen). Perolehan angka persentase ini dapat dikatakan berbading begitu jauh antara ya dan tidak. Sehingga, kesimpulan akhir peneliti menyatakan bahwa, factor Feel pada User Experience (UX) design mempengaruhi kemudahan pengguna dalam menggunakan aplikasi Carsworld sebesar 96\% (Sembilan Puluh Enam Persen).

Perolehan angka yang sangat tinggi untuk factor Feel dikarenakan aplikasi telah mampu, berdasarkan jawaban dari responden, dalam menfasilitasi mereka untuk melakukan Booking Online Service Mobil, dimana angka penilaian terhadap responden dalam variable ini mendapatkan angka 97\% (Sembilan Puluh Tujuh Persen). Selain itu, angka 97\% (Sembilan Puluh Tujug Persen) selanjutnya juga diraih pada variable pengguna akan menggunakan kembali aplikasi Carsworld untuk melakukan Booking Online Service Mobil. Sehingga, berdasarkan hal ini peneliti menyimpulkan bahwa User Expericence $(U X)$ desain telah menerapkan factor Feel dengan baik.

Sayangnya, developer perlu memberikan beberapa perubahan terhadap beberapa fitur atau fungsi agar pengguna dapat merasa mudah dalam menggunakan aplikasi Carsworld untuk melakukan Booking Online Service Mobil. Hal ini dikarenakan perolehan angka terhadap variable kemudahan penggunaan hanya mendapatkan angka 93\% (Sembilan Puluh Tiga Persen). 


\section{KESIMPULAN}

Berdasarkan hasil penelitian yang telah di bahas dalam pengaruh User Experience (UX) design tehadap kemudahan pengguna dalam menggunakan aplikasi Carsworld yang didasarkan kepada 3 (tiga) factor yang diperhatikan oleh perancang User Experience (UX) design pada aplikasi Carsworld dapat disimpulkan bahwa:

4. User Experience (UX) design pada Faktor Usability mempengaruhi kemudahan pengguna dalam menggunakan aplikasi Carsworld. Pengaruh factor Usability terhadap User Experience (UX) design mencapai angka 87\% (Delapan Puluh Tujuh Persen).

5. User Experience $(U X)$ design pada Faktor Look mempengaruhi kemudahan pengguna dalam menggunakan aplikasi Carsworld. Pengaruh factor Look terhadap User Experience $(U X)$ design mencapai angka 86\% (Delapan Puluh Enam Persen).

6. User Experience (UX) design pada Faktor Feel mempengaruhi kemudahan pengguna dalam menggunakan aplikasi Carsworld. Pengaruh factor Feel terhadap User Experience (UX) design mencapai angka 96\% (Sembilan puluh Enam Persen).

Dari ketiga factor User Experience (UX) design yang berpengaruh terhadap kemudahan pengguna dalam mengunakan aplikasi Carsworld, didapatkan bahwa factor Feel, memiliki pengaruh tertinggi. Kemudian dilanjutkan dengan factor Usability dan Look. Perbaikan perlu terus dilakukan oleh developer terkait User Experience (UX) design agar aplikasi mampu mencapai angka tertinggi dan mampu memberikan kemudahan bagi pengguna dalam melakukan Booking Online Service Mobil dengan aplikasi Carsworld.

Secara keseluruhan, User Experience (UX) design berpengaruh terhadap kemudahan pengguna dalam menggunakan aplikasi Carsworld.

\section{Bagi Developer User Experience (UX) design aplikasi Carsworld}

Saran peneliti bagi developer User Experience (UX) design aplikasi Carsworld telah dijabarkan dalam Analisa, namun point point kesimpulannya adalah sebagai berikut:

1. Peneliti menyarankan kepada pihak developer untuk melakukan perbaikan terhadap penyajian tata letak menu dan fungsi aplikasi. Perbaikan tata letak yang lebih memudahkan pengguna dalam menggunaka aplikasi Carsworld diperlukan.

2. Peneliti menyarankan kepada pihak developer untuk melakukan perbaikan terhadap pemilihan warna untuk aplikasi Carsworld. Pemilihan warna yang tepat dan sesuai akan memudahkan pengguna dalam menggunakan aplikasi.

3. Peneliti menyarankan kepada pihak developer untuk melakukan perbaikan terhadap konten aplikasi Carsworld agar pengguna dapat lebih mudah dalam menggunakan aplikasi dan melakukan transaksi dalam aplikasi Carsworld.

Perbaikan yang disarankan oleh peneliti kepada developer adalah agar pihak developer mampu memperbaiki aplikasi dan menyesuaikannya dengan kebutuhan pengguna. Kemudian, dalam jangka Panjang, aplikasi diharapkan mampu memudahkan pengguna dalam menggunakan aplikasi Carsworld dan menjadikan aplikasi Carsworld sebagai aplikasi pilihan mereka untuk melakukan Booking Online Service Mobil. 


\section{DAFTAR PUSTAKA}

Abidin, Z. (2018). Implementasi Sistem Pakar Di Bidang Otomotif Untuk Mendiagnosa Kerusakan Sepeda Motor Manual Non Injeksi Menggunakan Metode Certainty Factor Berbasis Web. Jurnal Teknologi Informasi dan Komunikasi, 104-115.

Agarina, M., Sutedi, \& Karim, A. S. (2019). Evaluasi User Interface Desain Menggunakan Metode Heuristics Pada Website Sistem Informasi Manajemen Seminar Institut Bisnis dan Informatika (IBI) Darmajaya. Seminar Nasional Hasil Penelitian dan Pengabdian, 192-200.

Allam, Z., \& Jones, D. S. (2021). Future (post-COVID) digital, smart and sustainable cities in the wake of 6G: Digital twins, immersive realities and new urban economies. Elsevier: Land Use Policy, Volume 101, 105201, DOI: https://doi.org/10.1016/j.landusepol.2020.105201.

Alrio, Y. S., Kharisma, A. P., \& Az-Zahra, H. M. (2018). Analisis Pengaruh User Experience Ride Sharing Application Terhadap Citra Merek Pada Pengguna Android dan iOS. Jurnal Pengembangan Teknologi Informasi dan Ilmu Komputer, 1-11.

Annisa, A. N., Suwandari, L., \& Adi, P. H. (2019). Analisis Pengaruh Customer Experience, User Experience, Dan Hambatan Berpindah Terhadap Minat Beli Ulang (Studi Pada Konsumen Go-Jek Di Kota Purwokerto). Journal and Proceeding Universitas Jendral Soedirman, 1-10.

Aries, T. M., Ranius, A. Y., \& Saputri, N. A. (2017). Usability Testing Untuk Mengukur Penggunaan Website Stik Bina Husada Palembang. Jurnal Teknik Informatika, Universitas Bina Darma Palembang, 1-12.

Aziati, Y. (2020). Analisis pengaruh user experience terhadap kepuasan pengguna mobile application e-commerce shopee menggunakan model delone \& mclean. Jakarta: Fakultas Sains dan Teknologi Universitas Islam Negeri Syarif Hidayatullah Jakarta.

Biduski, D., Bellei, E. A., Rodriguez, J. P., Zaina, L. A., \& Marchi, A. C. (2020). Assessing long-term user experience on a mobile health application through an in-app embedded conversation-based questionnaire. Elsevier: Computers in Human Behavior., Volume 104, 106169.

Bortko, K., Bartków, P., Jankowski, J., Kuras, D., \& Sulikowski, P. (2019). Multi-criteria Evaluation of Recommending Interfaces towards Habituation Reduction and Limited Negative Impact on User Experience. Elsevier: Procedia Computer Science, $\quad$ Volume $\quad 159, \quad 2240-2248, \quad$ DOI: https://doi.org/10.1016/j.procs.2019.09.399.

Carsworld. (2018). Sejarah Carsworld. Retrieved from Carsworld: https://carsworld.co.id/sejarah/ 
Demir, K. A., Döven, G., \& Sezen, B. (2019). Industri 5.0 and Human-Robot Co-working. Elsevier: Procedia Computer Science, Volume 158, 688-695, DOI: https://doi.org/10.1016/j.procs.2019.09.104.

Dzulkifli, A. M., Arifin, M. A., \& UmmuSalmah. (2020). Effect of the principles of good corporate governance on satisfaction of inpatients at Bahagia type c hospital, Makassar City. Elsevier: Enfermería Clínica, Volume 30, Supplement 4, June, 257-260, DOI: https://doi.org/10.1016/j.enfcli.2019.10.079.

Fitriana, D. E., \& Yanto, A. F. (2020). Analisis User Experience (Ux) Fitur Marketplace Facebook. Jurnal Ekonomi Dan Teknik Informatika Vol.8 No.2, 47-66.

Guimarães, E. A., Morato, Y. C., Carvalho, D. B., Oliveira, V. C., Pivatti, V. M., Cavalcante, R. B., . . . Dias, T. M. (2020). Evaluation of the Usability of the Immunization Information System in Brazil: A Mixed-Method Study. Telemedicine and e-Health, 1-10, DOI: https://doi.org/10.1089/tmj.2020.0077.

Kristianto, B. M. (2020). Pengaruh Sales Promotion Dan Desain Antarmuka Aplikasi Terhadap Impulse Buying Behavior Pengguna Layanan Gofood. Yogyakarta: Universitas Sanata Dharma.

Laksono, M. U. (2020). Evaluasi UI/UX Terhadap Accepted Usability Principles menggunakan Metode Heuristic Evaluation (Studi Kasus: SISTER Universitas Jember, User Level Mahasiswa). Jember: Universitas Jember.

Li, X., Zhao, X., Xu, W. (., \& Pu, W. (2020). Measuring ease of use of mobile applications in e-commerce retailing from the perspective of consumer online shopping behaviour patterns. Elsevier: Journal of Retailing and Consumer Services., Volume 55, 102093.

Luther, L., Tiberius, V., \& Brem, A. (2020). User Experience (UX) in Business, Management, and Psychology: A Bibliometric Mapping of the Current State of Research. Multimodal Technologies and Interaction, Vol. 4, No. 2, 18, DOI: https://doi.org/10.3390/mti4020018.

Münzer, M. G. (2020). How can augmented reality improve the user experience of digital products and engagement with cultural heritage outside the museum space? IOP Conference Series: Materials Science and Engineering, Volume 949, International Conference Florence Heri-tech: the Future of Heritage Science and Technologies, 1-8.

Nanda, C. G. (2020). Identifikasi Faktor Kualitas Kegunaan dan Konten Pada Website Institut Teknologi Sepuluh Nopember Surabaya untuk FItur Calon Mahasiswa. Surabaya: Institut Teknologi Sepuluh Nopember Surabaya .

Naser, H., Safari, B., \& Atmojo, K. (2020). Peran Serikat Pekerja Dalam Menghadapi Revolusi Industri 4.0 Pada Sektor Industri Otomotif. Jurnal Ilmu Manajemen dan Akuntansi., Vol. 8., No.1, 33-40. 
Paramitha, N. (2020). Perancangan Dan Evaluasi User Experience Menggunakan Design Thinking Pada Website Brosispku.Com. Pekanbaru: Universitas Islam Negeri Sultan Syarif Kasim Riau.

Park, H. S., Lee, G. A., Seo, B.-K., \& Billinghurst, M. (2020). User experience design for a smart-mirror-based personalized training system. Multimedia Tools and Applications, https://doi.org/10.1007/s11042-020-10148-5.

Prabowo, D. P., Yanuarsari, D. H., \& Pramunendar, R. A. (2020). Persepsi User Experience Terhadap Aplikasi Pesan Antar Makanan Online (Studi Kasus Pengguna Aplikasi Madhang.id). Jurnal Informatika Upgris., Vol. 6., No. 1, 4855.

Prasetyo, B., \& Trisyanti, U. (2019). Revolusi Industri 4.0 Dan Tantangan Perubahan Sosial. Prosiding SEMATEKSOS 3, 22-27.

Puspita, Y., Fitriani, Y., Astuti, S., \& Novianti, S. (2020). Selamat Tinggal Revolusi Industri 4.0, Selamat Datang Revolusi Industri 5.0. Prosiding Seminar Nasional Pendidikan Program Pascasarjana Universitas PGRI Palembang, 122-130.

Rizaldy, R., \& Dirgahayu, R. T. (2020). Pengembangan Front-End Sistem Informasi Pendataan Pendar Foundation Yogyakarta. AUTOMATA: Informatics Departement Universitas Islam Indonesia., Vol. 1., No. 2, 1-10.

Saputra, E. (2018). TA : Perancangan Desain User Interface/User Experience Layanan Informasi Kampus (Lik) dengan Metode Lean User Experience (Lean Ux) pada Universitas Dr. Soetomo. Surabaya: Universitas Dinamika Surabaya.

Shin, D., Zaid, B., \& Ibahrine, M. (2020). Algorithm Appreciation: Algorithmic Performance, Developmental Processes, and User Interactions. 2020 International Conference on Communications, Computing, Cybersecurity, and Informatics (CCCI), 1-5., DOI: 10.1109/CCCI49893.2020.9256470.

Sjödin, D., Parida, V., Kohtamäki, M., \& Wincent, J. (2020). An agile co-creation process for digital servitization: A micro-service innovation approach. Elsevier: Journal of Business Research, Volume 112, 478-491.

Wicaksono, A. H. (2018). Analisis Kepuasan Konsumen dan Kualitas Pelayanan Dalam Memberikan Pelayanan Konsumen Menggunakan Metode Importance Performance Analysis (Studi Pada Konsumen Waroeng Spesial Sambal). Tugas Akhir Teknik Industri, 1-93.

Yoon, J., \& Suh, M.-G. (2020). The key elements of strategic leadership capabilities to the latecomer firm: the case of RT Mart's success in the Chinese retail industri. Asia Pacific Business Review, 1-24. 